\title{
Performance study of drive systems and shunt FACTS for the operation of induction motors
}

\begin{abstract}
Drive systems are prevalent in industrial application of induction motors; while shunt FACTS devices are important to compensate disturbances and increase motor speeding up. In this paper an assessment study between Space Vector PWM (SVM) induction motor drive system and shunt FACTS (such as SVC) installed on terminals of motor is done. It is shown that shunt FACTS is more suitable than Induction motor drive system for decreasing of time of speeding up. The results of simulations also display that STATCOM has better response over SVC for improving dynamic behavior of induction motor and effectual for reduction of transients and refinement the voltage profile.
\end{abstract}

Keyword: Induction motor; Voltage source inverter (VSI); SVC; STATCOM 